\title{
IN SEARCH OF THE GREAT TRANSITION
}

Kinship networks and norms for the acceptance of marriages around the prohibition of incest is universal in today's hunter-gatherer societies. I suggest that kinship networks already existed in human populations around 200 ka ago in southern Africa.

\section{Osvaldo Nestor Herrera}

Independent researcher

e-mail: onherrera@protonmail.com

SUMMARY - According to Lévi-Strauss, all historically known hunter-gatherer societies formed networks of kinship relationships and norms for the acceptance of marriages around the prohibition of incest, which limits the number of possible marital unions favoring a more extensive system of links. I revisit an ethnographic study, conducted by the Marshall family with Ju/'hoan hunter-gatherers, to recognize the links between kinship and survival. I review recent results of genetic and paleoanthropological research that can inform us about the emergence of these new lifestyles. I suggest that kinship relationships and norms for the formation of marriages, with extensive networks of reciprocal relationships that favor survival, already existed in human populations around $200 \mathrm{ka}$ ago in southern Africa.

KEYWORDS - Kinship relationships, Prohibition of incest.

\section{INTRODUCTION}

The French anthropologist Claude Lévi-Strauss (Kuper 2009) published in 1949 one of his most important texts: Les structures élémentaires de la parenté, which he presented as an "introduction to a general theory of kinship systems" based on ethnographic information available mainly in the first half twentieth century.

According to Lévi-Strauss, all historically known hunter-gatherer societies formed networks of kinship relationships and norms for the acceptance of marriages around the prohibition of incest. The prohibition of incest, as a universal norm, is the answer to the universality of the instincts: there is a prohibition because there is desire. Prohibition can only be possible if there are cognitive capacities that include projecting possible futures and controlling present desires, which are exclusively human. The prohibition of incest limits the number of possible marital unions favoring a more extensive system of ties and alliances. In summary:

«Considered from the most general viewpoint, the incest prohibition expresses the transition from the natural fact of consanguinity to the cultural fact of alliance» 
If this "transition from the natural fact of consanguinity to the cultural fact of alliance" indicates a past process, no one has suggested yet, to my knowledge, when and why it occurred. The goal of this paper is to present a theory that accounts for the emergence of kinship relationships and norms for the formation of marriages, suggesting their chronology.

\section{EXPLORING EVIDENCE}

Three main parts of the Lévi-Strauss's expression just quoted can be explored, which allow building a theory about the emergence of kinship relationships and norms for the formation of marriages: (I) «the cultural fact of alliance» (II) «the incest prohibition» and (III) «the transition».

\section{(I) Ethnographic information and «the cultural fact of alliance»}

The Ju/'hoan hunter-gatherers numbered around a thousand people during the 50s, preserving a traditional way of life in the Nyae-Nyae area (South-West Africa, later Namibia) and in the Dobe area (Botswana), a region of the Kalahari in southern Africa, one of the more isolated parts of the arid savanna in southern Africa during the 20th century. Ju/'hoansi speak a !Kung dialect, so that they were referred to as !Kung people in the publications of the 50s to 70s.

The Marshall family began in 1950 a series of eight expeditions until 1961 in the Nyae-Nyae area, for an ethnographic study with Ju/'hoan nomadic hunter-gatherer groups. Also, Richard Lee and Irven DeVore began in 1963 another ethnographic study with Ju/'hoan hunter-gatherers in the Dobe area, focused heavily on ecology (Lee 1976).

Ju/'hoan families join together on the basis of consanguinity and affinity. One of these relationships links every individual to a family, each family to another family in a band (n/ / abesi), the unit in which families combine to live together in groups of viable size. A Ju/'hoan speaks of his territory (n!ore), as the place in which he lives or to which he belongs (Marshall 1976).

The interaction of the Ju/'hoan population as a whole in the region is governed by a kinship pattern. This pattern is based on and extends from the numerous actual kinship bonds. Intermarriage within the region has bound the people together across band demarcations (Marshall 1976).

They Ju/'hoansi visit relatives and friends. They visit for many reasons, for the pleasure of seeing people they like to be with, for change of scenery, to take gifts, to receive gifts, to arrange marriages, to take news of marriages, births and deaths, for solace in grief and to participate in rituals (Marshall 1976).

Ju/'hoan society, rigorously and without exception, requires that all men go to live with the parents of their brides and give them bride service. The duration of bride service is indefinite but people say it should be long enough for three children to be born (Marshall 1976).

The service a man gives is hunting. A man is responsible for the support of his parents and their dependents, and when he marries he becomes responsible as well for the support of his wife's parents and their dependents. If he moves from one band to another to give bride service, he takes with him those who need or 
want to accompany him. Bride service brings whole segments of bands to join other bands (Marshall 1976). The principal hunting time of the Ju/'hoan hunters is the search for the big animals. The big antelopes, because they go without drinking for long periods, do not come regularly to waterholes, they roam anywhere in the land, are widely scattered, singly or in herds of a few animals. When the hunters find spoor of the big animals, they follow it. The big antelopes are regularly hunted with poisoned arrows. The custom of meatsharing applies to the big animals which are deliberately hunted by hunting parties and the result is that everybody gets some meat, entailing a mutual obligation (Marshall 1976).

The owner of the animal is the owner of the first arrow to be effectively shot into the animal so that it penetrates enough for its poison to work. That person is responsible for the distribution. There may be several hunters in the hunting party and several arrows in the animal, but this seems to cause no confusion or conflict. Every arrow is known and the hunters can see which first penetrates effectively so that its poison could account for the kill. Each hunter gets a share of the meat anyway (Marshall 1976).

The first distribution the owner makes is to the hunters and to the giver of the arrow, if the arrow was not one the owner made himself. The meat, always uncooked in the first distribution, is given on the bone unless the animal is so large that the meat has been cut into strips at the kill (Marshall 1976).

In a second distribution, the several persons who got meat in the first distribution distribute them further. This meat also is given uncooked. A man's first obligation is to give to his wife's parents. He must give to them the best he has in generous portions as he can, while still fulfilling other primary obligations, which are to his own parents, his spouse, and his offspring (Marshall 1976).

Everyone who receives meat gives again, in another wave of sharing, to his or her parents, parents-in-law, spouse, offspring, siblings, and others. The meat may be cooked and the quantities small. The result of the distribution is that everybody gets some meat (Marshall 1976).

The Ju/'hoansi are quite conscious of the value of meat-sharing and they talk about it, especially about the benefit of the mutual obligation it entails, and the idea of sharing the meat obtained through hunting is deeply rooted (Marshall 1976).

In the Kalahari, there must be a permanent or semipermanent waterhole at which the band who inhabit the territory base themselves in the dry season. A lifestyle focused on sustaining peaceful ties allowed them to share a waterhole among various bands:

«!Kung bands have an entity that is visible to the eye. When the band encamps, the members cluster their fires together. If more than one band inhabits a territory and the bands encamp near the same waterhole, or if bands are visiting and are encamped near their hosts, the bands maintain a distinct separation. We had an unusually good opportunity to observe this particular characteristic during the drought of 1952 when five bands encamped themselves around the /Gam waterhole.» 
The behaviors that characterize Ju/'hoan groups, with extended family relationships and networks of reciprocal relationships, are expressed in wide but well-defined social spaces, favoring group survival even in unfavorable settings. Belonging to a territory and the existence of firm social ties with groups that live in the territory surroundings are assembled, allowing them to stay and to survive for long periods of time in a place, even in unfavorable conditions. Ju/’hoan families currently conserve the greatest nuclear-genetic diversity among all human populations, which shows continuity without population bottlenecks in southern Africa (Kim et al. 2014). The practice of sharing meat obtained from hunting large animals appears to be an important key in sustaining firm social ties.

\section{(II) Paleoanthropological information and «the incest prohibition»}

The norms for the acceptance of marriages and the prohibition of incest assume the prior existence of all the cognitive capacities that characterize current human populations. Cognitive capacities and brain shape are intimately related. Present-day modern humans have globular brains with steep frontal, bulging parietal, and enlarged, rounded cerebellar areas. Together with small and retracted faces, this globularity characterizes the modern human skull (Neubauer et al. 2018).

Fossil remains of hominids found in 1961 and 1962 in Jebel Irhoud (in Morocco, northwest Africa), with some morphological features characteristic of anatomically modern humans (Hublin et al. 2017), were recently dated to $315 \pm 34 \mathrm{ka}$ (Ritcher et al. 2017). These remains constitute evidence of an early phase in the evolution of the modern human lineage.

Given that both brain size and shape evolved independently and in parallel along the Neanderthal and anatomically modern human lineages over at least 400 thousand years, this might also imply that cognitive differences could have developed between the two species during that time (Stringer \& Galway-Witham 2017).

The anatomical differences between skulls belonging to Neanderthals and anatomically modern humans allow us to suppose the emergence of learning and social capacities exclusive to our species (Bastir et al. 2011). Anatomically modern humans have relatively larger cerebellar hemispheres, that are related to higher cognitive and social functions including language processing, the ability to produce and comprehend sounds and signs, which enables shared communication between individuals (Kochiyama et al. 2018), necessary for the constitution of human groups structured under kinship relationships.

\section{(III) Genetic information and «the transition»}

Mitochondrial DNA is transmitted maternally without recombination, accumulating changes slowly over generations, and determining the variability of mitogenomes. All known human mitogenomes derive from the mitogenome of a single female ancestor who lived thousands of years ago. The population to which that female ancestor belonged is the ancestral population. Calculations that use mitochondrial DNA as a molecular clock estimate when that female ancestor lived, the time of the most recent common ancestor (TMRCA) (Kivisild 2015). 
The first use of the human mitochondrial DNA as a molecular clock estimated our origin around 200 ka ago in Africa (Cann et al. 1987). A recent study estimated that the most recent common ancestor lived around 200 ka ago in Africa (Chan et al. 2019), coinciding with the first estimate.

Different paleoclimatic information, taken into account by the authors of this latest research, allowed them to suggest that the region where the ancestral population lived, the population to which the female ancestor belonged, was a wetland located in a now arid region of the Kalahari Plateau in southern Africa (in Botswana). By establishing mitogenomic timelines, frequencies and dispersals, they show that the L0 lineage emerged within the residual Makgadikgadi-Okavango palaeo-wetland of southern Africa, around 200 ka ago (Chan et al. 2019).

This palaeo-wetland surrounded by grasslands and forests, which has been proposed as an ancient refugium for several herbivores, including a zebra -Equus quagga- widely distributed now in the African savannas (Pedersen et al. 2018), could have met very favorable conditions for the survival of groups of huntergatherers, functioning also as a refugium for a human population.

Researchers tend to consider that the time of the most recent common ancestor (TMRCA) of all known mitochondrial lineages of current human populations, could point to a population bottleneck. But it could mean the beginning of the predominance in Africa of some human populations over others, now disappeared and unknown.

\section{THE THEORY}

A human phalanx found in 2010 in Denisova Cave, Altai Mountains (in Siberia), corresponds to a Neanderthal woman, the 'Altai Neanderthal'. The study of her nuclear genome revealed an inbreeding coefficient of $1 / 8$, indicating that her parents were closely related, that the parents of this Neanderthal individual were either half-siblings who had a mother in common, double first cousins, an uncle and a niece, an aunt and a nephew, a grandfather and a granddaughter, or a grandmother and a grandson (Prüfer et al. 2014). Provisionally, the genome of the 'Altai Neanderthal' allows us to suggest the absence of norms for the formation of marriages between Neanderthals, unlike today's hunter-gatherer societies. According to the inbreeding recorded and the just commented paleoanthropological information, the emergence of norms for the formation of marriages that characterize the human societies of our lineage could be located after the separation with the lineage that would lead to Neanderthals, as a result of the development of new cognitive capacities.

It is still unknown when were assembled the different cognitive capacities to shape hunter-gatherer societies as complex as those known ethnographically. I suggest that kinship relationships and norms for the formation of marriages, with extensive networks of reciprocal relationships that favor survival, were already established in human groups carrying the mitochondrial haplogroup L0, 200 ka ago in southern Africa. The populations derived from that ancestral population transmitted, in parallel to the mitogenomes, the new and more complex ways of life. The results of genetic studies, in which inbreeding can be estimated in human remains from Africa, will be able to test this assumption. 
There is still no firm evidence that ancient human groups were socially related, around 200 ka ago, as the Ju/'hoan families did during the fifties, but there are no firm arguments to rule out the existence of similar social relationships so long ago.

The formation of kinship relationships and rules for the formation of marriages could have arisen in the remote past together with networks of extensive reciprocity relationships that facilitated the distribution of the meat obtained through the hunting of large animals, and that favored survival group. The cognitive capacities of modern humans could be expressed, in the past, in the concern to strengthen social bonds and not necessarily in the production of artifacts that can allow archaeologists today to recognize these capacities, generating gaps between one and other expressions.

\section{FURTHER CONSIDERATIONS}

I suggest that the configuration of new and more complex social ties in an ancestral human population, more successful in terms of survival, marked the beginning of a way of life that would end with the predominance of that human lineage over other hominid lineages in which those ties did not exist. From this perspective, the configuration of new networks of reciprocal relationships favored the survival of modern hunter-gatherer groups that were dispersed throughout almost the entire planet, updating an out-of-Africa model (Scerri et al. 2019), which now includes a social component never before, according to my knowledge, taken into account. In anatomically modern humans scattered across the planet, limits could exist to accepting marriages out of the social space where networks of social relationships are expressed, considering Neanderthals and other hominids, as strangers. The limited gene flow that occurred between anatomically modern humans and other hominid lineages (Pääbo 2015) does not rule out this possibility.

According to different evidence, in particular the recovery of hunting tools at Schöningen archaeological site (in Germany) (Conard et al. 2020), it is considered that the skills for hunting animals were shared by several human lineages. In our lineage, the assay of new hunting modes and the emergence of new hunting-related technologies, such as the use of bows and arrows, could be the expression of modern cognitive abilities linked to the importance given to the large-bodied animal hunting.

The insistence on hunting large-bodied animals in the human groups that have dispersed throughout the planet during the last 50 thousand years (Martin 2005), could be an indicator of a way of life similar to that we know of the hunter-gatherer groups of the twentieth century. The importance given to hunting largebodied animals, instead of wanderlust (Tucci \& Akey 2016), could have been an important motivation for the exploration of new landscapes inhabited by animals more vulnerable to new and unknown hominid predators.

\section{Neanderthal disappearance}

Two deciduous molars of around 45-43 ka ago from Grotta del Cavallo (in Italy) account for the early presence of anatomically modern humans in Europe (Benazzi et al. 2011). The technological complex associated with these human remains includes blade and bladelet lithic assemblages, personal ornaments in 
the form of marine shell beads, worked bone, and colorants. The systematic use-traces analysis of 146 backed lithic pieces indicates that the main function of these pieces was hunting, as part of mechanically delivered projectiles (Sano et al. 2019).

The replacement of Neanderthals by anatomically modern humans, around 40 ka ago, is well known in Europe because of the good preservation of organic remains that allowed ancient DNA to be recovered for genetic studies and other organic remains to obtain radiocarbon dating. The coexistence of anatomically modern humans and Neanderthals could be estimated at 2.6-5.4 thousand years, not a rapid replacement of european Neanderthals by incoming anatomical modern humans (Higham et al. 2014; Douka 2019). Replacement processes of other Homo lineages occurred in other regions of the planet.

\section{The settlement of Siberia}

A human femur found in 2008, on the banks of the Irtysh River near the settlement of Ust'-Ishim, (western Siberia, in Russia), corresponds to an anatomically modern individual, the 'Ust'-Ishim modern human'. This hunter lived around 45 ka ago, probably during a warm period (Greenland Interstadial 12) that has been proposed to be a time of expansion of modern humans into Europe (Fu et al. 2014). According to the study of his nuclear genome, there is no evidence of recent inbreeding among the ancestors of the Ust'-Ishim individual (Fu et al. 2014).

In addition to the climatic conditions that could have favored the expansion of modern hunter-gatherer groups into cold latitudes, the ancestors of the 'Ust'-Ishim modern human' could have explored the region attracted by the presence of large-bodied animals. They could have contributed to the extinction of Elasmotherium, a rhino weighing 3.5 tons (Kosintsev et al. 2019), although no remains have yet been found in archaeological contexts.

\section{The settlement of Sahul}

Sahul, a single landmass formed by the union of Australia and New Guinea, was the first large landmass never occupied by hominids to which anatomically modern humans arrived. Hundreds of eggshell fragments were collected in recently eroded sand dunes from different regions of Australia, out of any obvious archaeological context. Many of these fragments have blackened ends due to their exposure to high temperatures, probably for cooking in ephemeral stoves following the same method used by Aboriginal Australians in historical times: relatively slow cooking of eggs wrapped in vegetation or buried in hot ashes (Miller et al. 2016). The oldest burned fragments are more likely to be around 53.9 ka ago and signal the beginnings of a continuous hunter presence until recent times (Miller et al. 2016).

The recently excavated Warratyi rock shelter archaeological site is located in one of the driest regions of Australia, was inhabited from around 49 ka ago by hunter-gatherer groups that coexisted with extinct fauna (Hamm et al. 2016). A fossil bone discovered in one of the oldest layers of the shelter belongs to Diprotodon, the largest of the Sahul marsupial mammals, a herbivore over 2 tonnes in weight that was probably hunted and consumed in that place (Hamm et al. 2016). In Australia the extinctions cut deeper into the fauna, leaving nothing above 45 kilograms alive, whereas much larger mammals managed to survive in Europe and 
the Americas (Johnson 2006).

Two recent genetic studies confirm the initial settlement of Sahul around 50 ka ago (Nagle et al. 2017; Tobler et al. 2017). One of these studies, which includes analysis of mitogenomes from hair samples of 111 aborigines, indicates that the initial settlement was followed by rapid migration along the eastern and western coast that reached southern Australia 49-45 ka ago (Tobler et al. 2017). Researchers found evidence of the continued presence of human populations in discrete geographic areas. The long-standing and diverse phylogeographic patterns documented are remarkable given the timescale involved, and raise the possibility that the central cultural attachment of Aboriginal Australians to 'country' may reflect the continuous presence of populations in discrete geographic areas for up to 50 thousand years (Tobler et al. 2017).

\section{CONCLUSIONS}

The Pinnacle Point archaeological site, a sea cave on the south coast of Africa (Marean et al. 2007), provides strong evidence that early humans displayed key elements of modern behaviors as far back as $165 \mathrm{ka}$ (McBrearty et al. 2007). Some researchers believe that modern cognitive capacity emerged at the same time as modern anatomy, around 200 ka ago, and that various aspects of human culture arose gradually over the course of subsequent millennia, shaping a package of modern human behaviors in Africa (McBrearty et al. 2007).

The formation of kinship networks and norms for the acceptance of marriages around the prohibition of incest is universal in today's hunter-gatherer societies. (Lévi-Strauss 1969 [1949]). I think that some recent studies, especially genetic ones, provide important clues to locate the beginnings of the formation of huntergatherer societies as complex as those known ethnographically. I suggest that these societies were already established 200 ka ago in southern Africa.

In this sense, I think that ethnographic information can be taken into account for the interpretation of social processes that occurred in the remote past. The well-established social ties allowed various groups Ju/'hoan to share a waterhole during a particularly dry season in the arid savanna in the fifties. The same social ties were able to allow to share, between several groups of hunters, the meat of a recently hunted large-bodied animal, such as a giant rhino, in the cold Arctic steppe.

\section{BIBLIOGRAPHY}

Bastir M, Rosas A, Gunz P, et al (2011) Evolution of the base of the brain in highly encephalized human species. Nature Communications 2:588

Benazzi S, Douka K, Fornai C, et al (2011) Early dispersal of modern humans in Europe and implications for Neanderthal behaviour. Nature 479:525-528

Cann R, Stoneking M, Wilson A, et al (1987) Mitochondrial DNA and human evolution. Nature 325:31-36

Chan E, Timmermann A, Baldi B, et al (2019) Human origins in a southern African palaeo-wetland and first 
migrations. Nature 575:185-189

Conard NJ, Serangeli J, Bigga G, et al (2020) A 300,000-year-old throwing stick from Schöningen, northern Germany, documents the evolution of human hunting. Nature Ecology \& Evolution 4:690-693

Douka K (2019) No hard borders for humans. Nature Ecology \& Evolution 3:157-158

Fu Q, Li H, Moorjani P, et al (2014) Genome sequence of a 45,000-year-old modern human from western Siberia. Nature 514:445-450

Hamm G, Mitchell P, Arnold LJ, et al (2016) Cultural innovation and megafauna interaction in the early settlement of arid Australia. Nature 539:280-283

Higham T, Douka K, Wood R, et al (2014) The timing and spatiotemporal patterning of Neanderthal disappearance. Nature 512:306-309

Hublin J-J, Ben-Ncer A, Bailey S, et al (2017) New fossils from Jebel Irhoud, Morocco and the pan- African origin of Homo sapiens. Nature 546:289-292

Johnson C (2006) Australia’s mammal extinctions: a 50,000 year history, Cambridge University Press, New York

Kim HL, Ratan A, Perry GH, et al (2014) Khoisan hunter-gatherers have been the largest population throughout most of modern-human demographic history. Nature Communications 5:5692

Kivisild T (2015) Maternal ancestry and population history from whole mitochondrial genomes. Investigative Genetics 6:3

Kochiyama T, Ogihara N, Tanabe HC, et al (2018) Reconstructing the Neanderthal brain using computational anatomy. Nature Scientific Reports 8:6296

Kosintsev P, Mitchell KJ, Devièse T, et al (2019) Evolution and extinction of the giant rhinoceros Elasmotherium sibiricum sheds light on late Quaternary megafaunal extinctions. Nature Ecology \& Evolution 3:31-38

Kuper A (2009) Claude Lévi-Strauss (1908-2009). Nature 562:862

Lee RB, DeVore I (1976) Kalahari Hunter-Gatherers. Studies of the !Kung San and The Neighbors, Harvard University Press, Cambridge, Massachusetts and London

Leví-Strauss C (1969) The Elementary Structures of Kinship, Bell JH, Von Sturmer JR (tr), Needham R (ed), Eyre \& Spottiswoode, London [Leví-Strauss C (1949) Les structures élémentaires de la parenté, Presses Universitaires de France, Paris]

Marean CW, Bar-Matthews M, Bernatchez J, et al (2007) Early human use of marine resources and pigment in South Africa during the Middle Pleistocene. Nature 449:905-908

Marshall L (1976) The !Kung of Nyae Nyae, Harvard University Press, Cambridge

Martin P (2005) Twilight of the mammoths: ice age extinctions and the rewilding of America, University of California Press, Berkeley and Los Angeles

McBrearty S, Stringer C (2007) The coast in colour. Nature 449:793-794 
Miller G, Magee J, Smith M, et al (2016) Human predation contributed to the extinction of the Australian megafaunal bird Genyornis newtoni 47 ka. Nature Communications 7:10496

Nagle N, van Oven M, Wilcox S, et al (2017) Aboriginal Australian mitochondrial genome variation - an increased understanding of population antiquity and diversity. Nature Scientific Reports 7:43041

Neubauer S, Hublin J-J, Gunz P (2018) The evolution of modern human brain shape. Science Advances 4:eaao5961

Pääbo S (2015) The diverse origins of the human gene pool. Nature 16:313-314

Pedersen C-E, Albrechtsen A, Etter P, et al (2018) A southern African origin and cryptic structure in the highly mobile plains zebra. Nature 2:491-498

Prüfer K, Racimo F, Patterson N, et al (2014) The complete genome sequence of a Neanderthal from the Altai Mountains. Nature 505:43-49

Ritcher D, Grün R, Joannes-Boyau R, et al (2017) The age of the hominin fossils from Jebel Irhoud, Morocco, and the origins of the Middle Stone Age. Nature 546:293-296

Sano K, Arrighi S, Stani C, et al (2019) The earliest evidence for mechanically delivered projectile weapons in Europe. Nature 3:1409-1414

Scerri E, Chikhi L, Thomas M (2019) Beyond multiregional and simple out-of-Africa models of human evolution. Nature 3:1370-1372

Stringer C, Galway-Witham J (2017) On the origin of our species. Nature 546:212-214

Tobler R, Rohrlach A, Soubrier J, et al (2017) Aboriginal mitogenomes reveal 50,000 years of regionalism in Australia. Nature 544:180-184

Tucci S, Akey J (2016) A map of human wanderlust. Nature 538:179-180 